\title{
AMADURECIMENTO E SENESCÊNCIA DE MAMÃO COM 1-METILCICLOPROPENO
} \author{
Camargo e Castro ${ }^{2}$ \\ ${ }^{1}$ Depto. de Produção Vegetal - USP/ESALQ, C.P. 9 - CEP: 13418-900 - Piracicaba, SP. \\ ${ }^{2}$ Depto. de Ciências Biológicas - USP/ESALQ. \\ ${ }^{3}$ Depto. de Fitotecnia - UFSM - CEP: $97119-900$ - Santa Maria, RS. \\ Bolsista CNPq. \\ *Autor correspondente<jacomino@esalq.usp.br>
}

Angelo Pedro Jacomino ${ }^{1,4 *}$; Ricardo Alfredo Kluge ${ }^{2,4}$; Auri Brackmann ${ }^{3,4}$; Paulo Roberto de

RESUMO: O mamão (Carica papaya L.) é uma fruta altamente perecível devido ao rápido amadurecimento após a colheita. A busca de técnicas que ampliem o período de conservação e reduzam as perdas póscolheita é desejável. Mamões 'Sunrise Solo' foram colhidos em dois estádios de maturação (verde e maduro) e tratados com o antagonista competitivo do etileno 1-metilciclopropeno (1-MCP) nas concentrações de 0 , 30,90 e $270 \mathrm{~nL} \mathrm{~L}^{-1}$, durante 12 horas a $20^{\circ} \mathrm{C}$. Após o tratamentos os frutos foram armazenados em condições ambientais $\left(20^{\circ} \mathrm{C}\right)$ durante oito dias. A aplicação do 1-MCP $\left(90\right.$ e $\left.270 \mathrm{~nL} \mathrm{~L}^{-1}\right)$ retardou a perda de coloração verde dos frutos e a incidência de podridões. Frutos verdes tratados com 1-MCP $\left(270 \mathrm{~nL} \mathrm{~L}^{-1}\right)$ apresentaram maior firmeza do que os frutos controle. O 1-MCP não afetou o conteúdo de sólidos solúveis dos frutos. A taxa respiratória e a produção de etileno foram reduzidas nos frutos tratados com 1-MCP $\left(90 \mathrm{~nL} \mathrm{~L}^{-1}\right.$ e $270 \mathrm{~nL}$ $\left.\mathrm{L}^{-1}\right)$ em ambos estádios de maturação. O 1-MCP $\left(90 \mathrm{~nL} \mathrm{~L}^{-1}\right.$ e $\left.270 \mathrm{~nL} \mathrm{~L}^{-1}\right)$ aumentou a vida de prateleira dos frutos do estádio verde de quatro para seis dias e dos frutos maduros de dois para quatro dias. Este bloqueador da ação do etileno mostrou-se eficiente para retardar o amadurecimento de mamões e aumentar sua vida de prateleira.

Palavras-chave: Carica papaya, 1-MCP, etileno, firmeza, armazenamento

\section{RIPENING AND SENESCENCE OF PAPAYA WITH 1-METHILCYCLOPROPENE}

\begin{abstract}
Papaya (Carica papaya L.) fruits are highly perishable due the fast ripening after harvest. The search for techniques that extend the shelf life and reduce the post-harvest losses is desirable. In this study, papaya 'Sunrise Solo' fruits were harvested in two ripening stages (green and ripe) and treated with the competitive ethylene antagonist 1-methycyclopropene (1-MCP) at concentrations of $0,30,90$ or $270 \mathrm{~nL} \mathrm{~L}^{-1}$ for $12 \mathrm{~h}$ at $20^{\circ} \mathrm{C}$ followed by storage at room temperature $\left(20^{\circ} \mathrm{C}\right)$ during eight days. Application of $1-\mathrm{MCP}(90$ or $\left.270 \mathrm{~nL} \mathrm{~L}^{-1}\right)$ delayed degreening decay. Green fruits treated with 1-MCP $\left(270 \mathrm{~nL} \mathrm{~L}^{-1}\right)$ presented higher firmness in relation to control fruits. 1-MCP did not affect the soluble solids of fruits. The respiration rate and ethylene production were lower in fruits treated with 1-MCP $\left(90\right.$ or $\left.270 \mathrm{~nL} \mathrm{~L}^{-1}\right)$ in both ripening stages. 1-MCP extended the shelf life of green fruits from four to six days and the shelf life of ripe fruits from two to four days. The 1MCP was efficient to delay the ripening of papayas extending their shelf life.

Key words: Carica papaya, 1-MCP, ethylene, firmness, storage
\end{abstract}

\section{INTRODUÇÃO}

O mamão (Carica papaya L.) é uma das frutas mais cultivadas do mundo, especialmente em áreas tropicais onde a temperatura média anual é de $25^{\circ} \mathrm{C}$ (Simão, 1998). O Brasil é o maior produtor mundial de mamão, perfazendo cerca de $35 \%$ do total produzido.

O mamão é um fruto climatérico cujas transformações resultantes do amadurecimento ocorrem rapidamente após a colheita do fruto fisiologicamente maduro, desencadeadas pela produção do etileno e aumento da taxa respiratória. Isso o caracteriza como um fruto bastante perecível em pós-colheita (Paull, 1993). Dada essa alta perecibilidade, o controle do amadurecimento é fundamental para o aumento na vida útil após a colheita, visando o mercado interno e exportação de frutas. Os principais fatores que depreciam a qualidade pós-colheita do mamão são o rápido amolecimento e a elevada incidência de podridões.

A preservação do mamão em temperatura ambiente é desejável, uma vez que a quase totalidade da fruta comercializada ao nível de varejo, no Brasil, encontra-se sem refrigeração. A manutenção da qualidade do mamão nesta condição pode facilitar o transporte a longas distâncias e ampliar o período de comercialização.

$\mathrm{O}$ etileno $\left(\mathrm{C}_{2} \mathrm{H}_{4}\right)$ está envolvido na aceleração do amadurecimento e senescência de frutos climatéricos. Em determinado estádio da maturação, o etileno se liga ao seu receptor na célula, um complexo protéicoenzimático, e desencadeia uma série de eventos que culminam com o amadurecimento e senescência do fruto 
(Burg \& Burg, 1967; Lelièvre et al., 1997a). Tem sido verificado que a inibição da ligação do etileno ao seu receptor pode reduzir a produção e a ação do mesmo e, com isso, retardar o amadurecimento e a senescência de frutos climatéricos.

Vários compostos são capazes de bloquear a ligação do etileno ao seu receptor na célula, causando inibição dos efeitos deste hormônio, como é o caso do 2,5-norbornadieno (NBD) e do diazociclopentadieno (DACP). Foi verificado que estes compostos retardam o amolecimento e amadurecimento de maçãs (Blankenship \& Sisler, 1989 e 1993; Gong \& Tian, 1998). Entretanto, estes compostos não são comercialmente aceitos devido à sua toxidez.

O 1-metilciclopropeno (1-MCP ou $\mathrm{C}_{4} \mathrm{H}_{6}$ ) é um composto volátil recentemente descoberto e que tem demonstrado ser um potente inibidor da ação do etileno (Serek et al., 1995). Embora o 1-MCP seja um gás, tem sido formulado em pó, o qual libera o 1-MCP quando misturado a uma solução básica ou água. O 1-MCP ligase fortemente ao sítio do etileno, evitando a ligação e a ação do mesmo.

O 1-MCP retarda a senescência de flores cortadas e de plantas envasadas quando aplicado em baixíssimas concentrações, ao nível de $\mathrm{nL} \mathrm{L}^{-1}$ (Serek et al., 1994 e 1995; Porat et al., 1995; Sisler et al., 1996). Em recentes estudos foi verificado que o 1-MCP, além de restringir a ação do etileno, pode reduzir sua produção e retardar o amadurecimento de muitos frutos climatéricos, como pêra (Lelièvre et al., 1997b), maçã (Fan et al., 1999), banana (Sisler \& Serek, 1997; Golding et al., 1998; Jiang et al., 1999), ameixa (Abdi et al., 1998), damasco (Feng et al., 2000), abacate (Fan et al., 2000) e tomate (Nakatsuka et al., 1997; Sisler \& Serek, 1997).

Considerando a potencialidade do 1-MCP em retardar o amadurecimento de frutos climatéricos, o objetivo do presente trabalho foi avaliar o efeito inibitório desse bloqueador da ação do etileno sobre o amadurecimento e senescência de mamão após a colheita.

\section{MATERIAL E MÉTODOS}

O experimento foi realizado no Departamento de Produção Vegetal da USP/ESALQ, em Piracicaba, SP, Brasil. Foram utilizados mamões 'Sunrise Solo' linhagem 72/12, colhidos no município de Teixeira de Freitas, BA. A colheita foi realizada no dia $24 / 05 / 2000$ e os frutos foram transportados até a CEAGESP, na cidade de São Paulo, SP, onde chegaram no dia 26/05/2000.

No recebimento, os mamões foram imediatamente selecionados. Utilizaram-se frutos sem defeitos, com peso médio de $400 \pm 27 \mathrm{~g}$, em dois estádios de maturação: a) verde: frutos com coloração verde e uma lista amarela e, b) maduro: frutos com coloração verde e três ou quatro listas amarelas.

Os frutos foram submetidos a $0,30,90$ e $270 \mathrm{~nL}$ $\mathrm{L}^{-1}$ de 1-MCP. A aplicação constou da colocação dos frutos em câmara hermética e exposição ao produto por um período de 12 horas sob temperatura de $20^{\circ} \mathrm{C}$. Os frascos foram abertos no interior das câmaras, as quais foram fechadas imediatamente para evitar a perda do gás. Após 12 horas de tratamento, as câmaras foram abertas e os frutos foram colocados em condições ambientais $\left(20^{\circ} \mathrm{C}\right)$, sendo avaliados a cada dois dias, durante oito dias.

O delineamento experimental adotado foi inteiramente casualizado em esquema fatorial para cada estádio de maturação. Foram utilizadas quatro repetições de cinco frutos por parcela.

As variáveis determinadas foram: a) coloração da casca: usando-se colorímetro, com os resultados expressos em ângulo de cor $\left(\mathrm{h}^{\circ}\right)$. $\mathrm{O} \mathrm{h}^{\circ}$ define a coloração básica, onde $0^{\circ}=$ vermelho, $90^{\circ}=$ amarelo e $180^{\circ}=$ verde (McGuire, 1992); b) firmeza de polpa: pelo método da aplanação (Calbo \& Nery, 1995), c) podridões: foi calculada a porcentagem de frutos afetados em cada repetição e a severidade das lesões (frutos não afetados, pouco ou muito afetados). Foram considerados pouco afetados aqueles frutos com início de podridão na região peduncular e/ou lesão $\leq 1 \mathrm{~cm}$ na superfície da casca. $O$ agente causal foi identificado por sintomatologia e análise microscópica; d) teor de sólidos solúveis: em refratômetro digital; e) taxa respiratória e f) produção de etileno.

Para a determinação da taxa respiratória e da produção de etileno, amostras de frutos foram acondicionadas em câmaras herméticas, que foram mantidas fechadas durante três horas. Posteriormente, coletou-se uma amostra de $2 \mathrm{~L}$ em um recipiente de polietileno tereftalato que foi enviado ao laboratório do Núcleo de Pesquisa em Pós-Colheita da UFSM, em Santa Maria, RS. Determinou-se a concentração de etileno em cromatógrafo a gás com coluna Porapak $\mathrm{N}$ e detector de ionização de chama (FID). A temperatura da coluna, injetor e detector foi de 90,140 e $200^{\circ} \mathrm{C}$, respectivamente. De cada amostra de gás, foram extraídas duas amostra de $1 \mathrm{~mL}$ com seringa plástica descartável e injetadas no cromatógrafo. As áreas de pico de etileno foram transformadas em ppm através de um fator de correção obtido pela injeção de um gás padrão com 10 ppm de etileno. Para o cálculo da produção de etileno, foram levados em consideração o volume da câmara de armazenamento (60 L), a massa dos frutos e o tempo de acúmulo de etileno.

Para a determinação da respiração (produção de $\left.\mathrm{CO}_{2}\right)$ utilizou-se um analisador de gases $\left(\mathrm{CO}_{2}\right.$ e $\left.\mathrm{O}_{2}\right)$. Os gases das amostras foram conduzidos pelo analisador até a estabilização dos valores das concentrações de $\mathrm{CO}_{2}$, expressos em porcentagem. Também para o cálculo da respiração, foram levados em consideração o volume da câmara de armazenamento, a massa de frutos e o tempo de acúmulo de $\mathrm{CO}_{2}$.

Os resultados foram submetidos a análise de variância, comparação de médias e regressão polinomial. 


\section{RESULTADOS E DISCUSSÃO}

Os frutos do estádio verde tratados com 90 ou 270 $\mathrm{nL} \mathrm{L}^{-1}$ de 1-MCP apresentaram perda de coloração verde mais lenta do que os frutos não tratados ou tratados com $30 \mathrm{~nL} \mathrm{~L}^{-1}$ (Tabela 1). Para os frutos do estádio maduro verificou-se diferença consistente apenas entre os frutos tratados com $270 \mathrm{~nL} \mathrm{~L}^{-1}$ e os frutos não tratados. O desverdecimento é decorrente da quebra da estrutura da molécula de clorofila, envolvendo a atividade da enzima clorofilase. A elevação da atividade desta enzima está geralmente associada com a produção de etileno durante o amadurecimento do fruto (Tucker, 1993). O 1-MCP se liga ao sítio de ligação do etileno na célula evitando a ação do mesmo sobre os processos fisiológicos de amadurecimento (Serek et al., 1995). Assim, a perda de cor verde, resultante do processo normal de amadurecimento, foi retardada com a aplicação do 1-MCP. A retenção do desenvolvimento da coloração da casca em frutos tratados com 1-MCP também foi verificada em ameixa (Abdi et al., 1998), banana (Golding et al., 1998), tomate (Dupille \& Sisler, 1995) e abacate (Fan et al., 2000).

O 1-MCP afetou significativamente a porcentagem de frutos com podridões ao longo do período de armazenamento (Tabela 2). Os fungos mais frequentemente encontrados foram os dos gêneros Colletrotrichum e Phomopsis.

Para o estádio verde, as podridões aumentaram sensivelmente aos 6 dias de conservação a $20^{\circ} \mathrm{C}$. Os frutos do controle ou tratados com $30 \mathrm{~nL} \mathrm{~L}^{-1}$ de 1-MCP apresentaram porcentagem de podridão significativamente superior aos frutos tratados com 90 ou $270 \mathrm{~nL}$ $\mathrm{L}^{-1}$. Embora neste período tenha sido observada porcentagem de 15 a $20 \%$ de podridão nos frutos tratados com as maiores concentrações, estas podridões foram consideradas de baixa severidade (Tabela 3 ), tendo sido constatado apenas início de podridão peduncular, sendo a área afetada inferior a $5 \%$ da superfície do fruto. Assim, aos 6 dias de conservação a $20^{\circ} \mathrm{C}$, os frutos tratados com 90 ou $270 \mathrm{~nL} \mathrm{~L}^{-1}$ de 1 -MCP encontravam-se aptos para a comercialização, ao contrário dos frutos controle ou tratados com $30 \mathrm{~nL} \mathrm{~L}^{-1}$. Aos 8 dias, todos os tratamentos deste estádio encontravam-se com alta porcentagem de podridão e alta severidade das lesões (Tabelas 2 e 3 ).

Para o estádio maduro, os frutos não apresentaram podridão aos 2 dias de armazenamento a $20^{\circ} \mathrm{C}$, ao passo que aos 4 dias a porcentagem de podridão variou de 15 a $20 \%$ (Tabela 2). Os frutos não tratados ou tratados com $30 \mathrm{~nL} \mathrm{~L}^{-1}$ apresentaram maior severidade de podridão (Tabela 3). Nesses, $50 \%$ apresentaram podridão peduncular e lesões com mais de $1 \mathrm{~cm}$ de diâmetro na casca, o que descartou os frutos deste tratamento para a comercialização aos 4 dias. Os frutos tratados com 90 ou $270 \mathrm{~nL} \mathrm{~L}^{-1}$ de 1-MCP apresentaram, neste período, percentual de podridão de $15 \%$, sendo que a totalidade dos frutos afetados apresentaram início de podridão peduncular e ausência de lesões na casca. Aos 6 dias de conservação todos os tratamentos estavam inaptos para a comercialização, considerando as altas porcentagens de podridão e a severidade das lesões.

Os frutos tratados com 1-MCP, principalmente nas concentrações de $90 \mathrm{~nL} \mathrm{~L}^{-1}$ e $270 \mathrm{~nL} \mathrm{~L}^{-1}$ apresentaram menor perda de firmeza durante os períodos de avaliação (Tabela 4), diferindo significativamente do controle em ambos estádios de maturação. Frutos tratados com $30 \mathrm{~nL} \mathrm{~L}^{-1}$ de 1-MCP apresentaram comportamento intermediário. A firmeza de polpa do fruto é determinada pela força de coesão entre as pectinas. Com a evolução do amadurecimento ocorre atuação de enzimas pectinolíticas, que transformam a pectina insolúvel em solúvel e promovem o amolecimento dos frutos. $\mathrm{O}$ amolecimento dos frutos é um dos processos

Tabela 1 - Efeito do 1-MCP na cor da casca (ângulo de cor) de mamões 'Sunrise Solo' colhidos em dois estádios de maturação e armazenados a $20^{\circ} \mathrm{C}^{1}$.

\begin{tabular}{|c|c|c|c|c|c|c|}
\hline \multirow{3}{*}{ Estádio de Maturação } & \multirow{3}{*}{$\begin{array}{c}\text { Concentração de 1-MCP } \\
\qquad \mathrm{nL} \mathrm{L-1}\end{array}$} & \multicolumn{5}{|c|}{ Dias a $20^{\circ} \mathrm{C}$} \\
\hline & & 0 & 2 & 4 & 6 & 8 \\
\hline & & ------- & 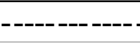 & -- Ângulo d & $\left.h^{\circ}\right)$ & 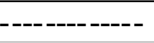 \\
\hline \multirow[t]{4}{*}{ Verde } & 0 & 117,40 & $100,90 \mathrm{~b}$ & $90,57 \mathrm{~b}$ & 82,92 b & $79,92 \mathrm{~b}$ \\
\hline & 30 & 117,40 & $107,14 a$ & 94,52 b & 81,37 b & 79,67 b \\
\hline & 90 & 117,40 & $109,80 a$ & $102,72 \mathrm{a}$ & 89,75 a & $81,55 a b$ \\
\hline & 270 & 117,40 & $112,25 \mathrm{a}$ & 111,25 a & 89,27 a & 86,87 a \\
\hline$F$ (trat.) & & & ** & ** & ** & * \\
\hline \multirow[t]{3}{*}{ C.V. (\%) } & & & 3,18 & 2,73 & 3,71 & 3,76 \\
\hline & & & . & Ângulo d & $\left.h^{\circ}\right)$ & 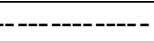 \\
\hline & 0 & 105,02 & $86,75 \mathrm{c}$ & $82,05 \mathrm{c}$ & $78,15 b$ & $74,09 \mathrm{~b}$ \\
\hline \multirow[t]{3}{*}{ Maduro } & 30 & 105,02 & $91,97 b$ & 85,82 bc & $79,44 a b$ & $75,94 a b$ \\
\hline & 90 & 105,02 & $93,25 \mathrm{~b}$ & $88,62 \mathrm{~b}$ & $81,25 a b$ & $76,20 a b$ \\
\hline & 270 & 105,02 & $100,15 a$ & 95,27 a & 83,80 a & 78,25 a \\
\hline$F$ (trat.) & & & ** & ** & ** & ** \\
\hline C.V. (\%) & & & 3,19 & 3,46 & 2,34 & 1,65 \\
\hline
\end{tabular}

${ }^{1}$ Médias seguidas de mesma letra na coluna não diferem pelo teste de Tukey a $5 \%$.

*, **significativo a $\mathrm{P} \leq 0,05$ e $\mathrm{P} \leq 0,01$, respectivamente. 
Tabela 2 - Efeito do 1-MCP na porcentagem de podridão em mamões 'Sunrise Solo' colhidos em dois estádio de maturação e armazenadas a $20^{\circ} \mathrm{C}^{1}$.

\begin{tabular}{|c|c|c|c|c|c|c|}
\hline \multirow[t]{3}{*}{ Estádio de Maturação } & \multirow{3}{*}{$\begin{array}{c}\text { Concentração de 1-MCP } \\
n L L^{-1}\end{array}$} & \multicolumn{5}{|c|}{ Dias a $20^{\circ} \mathrm{C}$} \\
\hline & & 0 & 2 & 4 & 6 & 8 \\
\hline & & ----- & 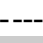 & Poc & \%) --- & \\
\hline \multirow[t]{4}{*}{ Verde } & 0 & 0 & 0 & 5 & $55 a$ & $100 a$ \\
\hline & 30 & 0 & 0 & 5 & $40 a$ & $100 a$ \\
\hline & 90 & 0 & 0 & 5 & $20 \mathrm{~b}$ & $50 \mathrm{~b}$ \\
\hline & 270 & 0 & 0 & 5 & $15 \mathrm{~b}$ & $30 \mathrm{~b}$ \\
\hline$F$ (trat.) & & & & NS & ** & ** \\
\hline \multirow[t]{3}{*}{ C.V. (\%) } & & & & 17,11 & 15,71 & 13,87 \\
\hline & & $-\cdots$ & --- & $--\mathrm{Poc}$ & 6)------- & -------- \\
\hline & 0 & 0 & 0 & 20 & $95 a$ & 100 \\
\hline \multirow[t]{3}{*}{ Maduro } & 30 & 0 & 0 & 20 & $95 a$ & 100 \\
\hline & 90 & 0 & 0 & 15 & $75 \mathrm{~b}$ & 100 \\
\hline & 270 & 0 & 0 & 15 & $65 \mathrm{~b}$ & 90 \\
\hline$F$ (trat.) & & & & NS & * & NS \\
\hline C.V. (\%) & & & & 20,17 & 25,23 & 12,66 \\
\hline
\end{tabular}

${ }^{1}$ Médias seguidas de mesma letra na coluna não diferem pelo teste de Tukey a $5 \%$.

NS, ${ }^{*},{ }^{* *}=$ não significativo e significativo a $\mathrm{P} \leq 0,05$ e 0,01 , respectivamente.

Tabela 3 - Efeito do 1-MCP na severidade de podridões em mamões 'Sunrise Solo' armazenados a $20^{\circ} \mathrm{C}$ '.

\begin{tabular}{|c|c|c|c|c|c|c|c|c|c|c|c|c|c|c|c|c|}
\hline \multirow[t]{3}{*}{$\begin{array}{l}\text { Estádio } \\
\text { deMaturação }\end{array}$} & \multirow[t]{2}{*}{$\begin{array}{c}\text { Concentração } \\
\text { de 1-MCP }\end{array}$} & \multicolumn{15}{|c|}{ Dias a $20^{\circ} \mathrm{C}$} \\
\hline & & 0 & 2 & 4 & 6 & 8 & 0 & 2 & 4 & 6 & 8 & 0 & 2 & 4 & 6 & 8 \\
\hline & $\mathrm{nL} \mathrm{L}^{-1}$ & \multicolumn{5}{|c|}{$\%$ de frutos pouco afetados } & \multicolumn{5}{|c|}{$\%$ de frutos muito afetados } & \multicolumn{5}{|c|}{ \% de frutos não afetados } \\
\hline \multirow[t]{4}{*}{ Verde } & 0 & 0 & 0 & 5 & 35 & 0 & 0 & 0 & 0 & 20 & 100 & 100 & 100 & 95 & 45 & 0 \\
\hline & 30 & 0 & 0 & 5 & 20 & 0 & 0 & 0 & 0 & 20 & 100 & 100 & 100 & 95 & 60 & 0 \\
\hline & 90 & 0 & 0 & 5 & 20 & 20 & 0 & 0 & 0 & 0 & 30 & 100 & 100 & 95 & 80 & 50 \\
\hline & 270 & 0 & 0 & 5 & 15 & 15 & 0 & 0 & 0 & 0 & 15 & 100 & 100 & 95 & 85 & 70 \\
\hline \multirow[t]{4}{*}{ Ma duro } & 0 & 0 & 0 & 10 & 0 & 0 & 0 & 0 & 10 & 95 & 100 & 100 & 100 & 80 & 5 & 0 \\
\hline & 30 & 0 & 0 & 10 & 10 & 0 & 0 & 0 & 10 & 85 & 100 & 100 & 100 & 80 & 5 & 0 \\
\hline & 90 & 0 & 0 & 15 & 50 & 10 & 0 & 0 & 0 & 25 & 90 & 100 & 100 & 85 & 25 & 0 \\
\hline & 270 & 0 & 0 & 15 & 40 & 10 & 0 & 0 & 0 & 25 & 90 & 100 & 100 & 85 & 35 & 0 \\
\hline
\end{tabular}

${ }^{1}$ Considerou-se como frutos pouco afetados aqueles com início de podridão peduncular ou com lesão sobre a casca com menos de $1 \mathrm{~cm}$ de diâmetro, e muito afetados aqueles com podridão peduncular avançada e/ou podridão sobre a casca com lesão superior a $1 \mathrm{~cm}$ de diâmetro.

do amadurecimento mais sensíveis ao etileno (Lelièvre et al., 1997a). A maior firmeza dos frutos tratados com as maiores concentrações de 1-MCP está provavelmente associada à redução da atividade das enzimas pectinolíticas, causada pela redução da ação do etileno. Resultados similares a estes foram obtidos em maçã (Fan et al., 1999) e banana (Jiang et al., 1999).

O teor de sólidos solúveis não foi influenciado pelo 1-MCP, em ambos estádio de maturação; variou de 11,15 a $12,01^{\circ}$ Brix para o estádio verde e de 12,74 a $13,62^{\circ}$ Brix para o estádio maduro, durante o amadurecimento.

O 1-MCP reduziu a taxa respiratória e a produção de etileno dos frutos nos dois estádios de maturação (Figura 1). As concentrações de 90 e $270 \mathrm{~nL}$ $\mathrm{L}^{-1}$ apresentaram as maiores reduções nestes processos, enquanto que, na concentração de $30 \mathrm{~nL} \mathrm{~L}^{-1}$, os resultados pouco diferiram do controle. $\mathrm{O}$ aumento na produção de etileno precedeu a ascensão climatérica da respiração, mostrando o efeito indutor do etileno sobre o processo respiratório.

O 1-MCP é caracterizado por ser um competidor pelo sítio de ligação do etileno na célula. Quando aplicado no momento correto, o 1-MCP ocupa os sítios de ligação do etileno e impede os seus efeitos, como por exemplo a síntese de enzimas degradativas, aumento na taxa respiratória e a própria produção de etileno (autocatálise). A capacidade de conservação de um produto hortícola está inversamente relacionada à taxa respiratória, e em muitos casos, com a taxa de produção de etileno (Kader, 1994). A redução na produção de etileno e na taxa respiratória explicam a maior conservação dos frutos tratados com 90 e $270 \mathrm{~nL} \mathrm{~L}^{-1}$ de 1-MCP. A menor taxa respiratória e menor produção de etileno de frutos tratados com 1-MCP também foi reportada em trabalhos anteriores (Abdi et al., 1998; Golding et al., 1998; Fan et al., 1999; Jiang et al., 1999).

A firmeza da polpa e a porcentagem de podridão foram considerados os principais fatores que influenciaram a vida de prateleira dos frutos deste experimento. Desta forma, para frutos no estádio verde tratados com 1-MCP (90 ou $270 \mathrm{~nL} \mathrm{~L}^{-1}$ ), a máxima capacidade de armazenamento foi de 6 dias, enquanto que os frutos não tratados ou os tratados com $30 \mathrm{~nL} \mathrm{~L}^{-1}$ apresentaram vida de prateleira de 4 dias. Para o estádio maduro, a máxima capacidade de armazenamento foi de 
4 dias para os frutos tratados com 1-MCP (90 ou $270 \mathrm{~nL} \mathrm{~L}^{-1}$ ) e 2 dias para os não tratados ou tratados com $30 \mathrm{~nL} \mathrm{~L}^{-1}$.

Levando-se em consideração a firmeza de polpa realizou-se regressão polinomial para as concentrações de 1-MCP nos máximos períodos de armazenamento para os dois estádio de maturação. Para tal, fixou-se o tempo máximo de conservação observado no presente experimento em seis dias para o estádio verde e quatro dias para o estádio maduro. Tanto no estádio verde (Figura 2A) quanto no estádio maduro (Figura 2B) esta variável apresentou comportamento linear. Portanto, para determinar a máxima capacidade de manutenção de firmeza seria necessário avaliar concentrações superiores a $270 \mathrm{~nL} \mathrm{~L}^{-1}$. Por outro lado, frutos com firmeza acima de $1,0 \mathrm{kgf} \mathrm{cm}^{-2}$ encontravam-se excessivamente firmes. Isso pode reduzir a aceitação comercial dos frutos, pois, embora a coloração externa estivesse amarela, os frutos não amoleceram adequadamente. Este comportamento foi observado nos frutos mais verdes (ausência de listas amarelas) tratados com $270 \mathrm{~nL} \mathrm{~L}^{-1}$ de 1-MCP.

Para a porcentagem de podridão, as concentrações de 90 e $270 \mathrm{~nL} \mathrm{~L}^{-1}$ de 1-MCP promoveram os melhores resultados, com valores entre 15 e $20 \%$ (Figura 3).

Para o estádio maduro não houve significância das concentrações de 1-MCP sobre o percentual de podridões aos quatro dias (Tabela 2), enquanto que para a variável firmeza verificou-se significância da regressão linear, ou seja, a firmeza aumenta à medida em que a concentração de 1-MCP é incrementada (Figura 2).

Tabela 4 - Efeito do 1-MCP sobre a firmeza de mamões 'Sunrise Solo' colhidos em dois estádio de maturação e armazenados a $20^{\circ} \mathrm{C}^{1}$.

\begin{tabular}{|c|c|c|c|c|c|c|}
\hline \multirow[t]{3}{*}{ Estádio de Maturação } & \multirow{3}{*}{$\begin{array}{c}\text { Concentração de 1-MCP } \\
n L L^{-1}\end{array}$} & \multicolumn{5}{|c|}{ Dias a $20^{\circ} \mathrm{C}$} \\
\hline & & 0 & 2 & 4 & 6 & 8 \\
\hline & & \multicolumn{5}{|c|}{ 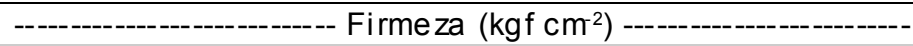 } \\
\hline \multirow[t]{4}{*}{ Verde } & 0 & 1,82 & 0,97 & $0,58 b$ & $0,56 \mathrm{c}$ & $0,48 \mathrm{~b}$ \\
\hline & 30 & 1,82 & 1,05 & $0,78 a b$ & $0,71 \mathrm{bc}$ & $0,49 \mathrm{~b}$ \\
\hline & 90 & 1,82 & 1,27 & $1,21 \mathrm{a}$ & $0,94 \mathrm{ab}$ & $0,76 \mathrm{ab}$ \\
\hline & 270 & 1,82 & 1,30 & $1,24 a$ & $1,11 \mathrm{a}$ & $1,10 \mathrm{a}$ \\
\hline$F$ (trat.) & & & NS & ** & ** & ** \\
\hline \multirow[t]{3}{*}{ C.V. (\%) } & & & 24.36 & 23,77 & 20,23 & 19,97 \\
\hline & & \multicolumn{5}{|c|}{ 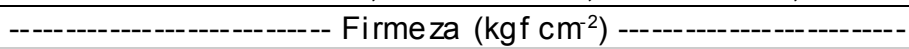 } \\
\hline & 0 & 1,11 & $0,54 \mathrm{~b}$ & $0,41 b$ & $0,33 c$ & - \\
\hline \multirow[t]{3}{*}{ Maduro } & 30 & 1,11 & $0,58 \mathrm{~b}$ & $0,53 b$ & $0,45 \mathrm{bc}$ & - \\
\hline & 90 & 1,11 & $0,67 \mathrm{ab}$ & $0,60 \mathrm{~b}$ & $0,56 \mathrm{~b}$ & - \\
\hline & 270 & 1,11 & $0,90 \mathrm{a}$ & $0,89 a$ & $0,87 \mathrm{a}$ & - \\
\hline F (trat.) & & & * & $* *$ & ** & \\
\hline C.V. (\%) & & & 21,74 & 21,88 & 19,23 & \\
\hline
\end{tabular}

${ }^{1}$ Médias seguidas de mesma letra na coluna não diferem pelo teste de Tukey a $5 \%$.

NS, ${ }^{*},{ }^{* *}=$ não significativo e significativo a $\mathrm{P} \leq 0,05$ e 0,01 , respectivamente.
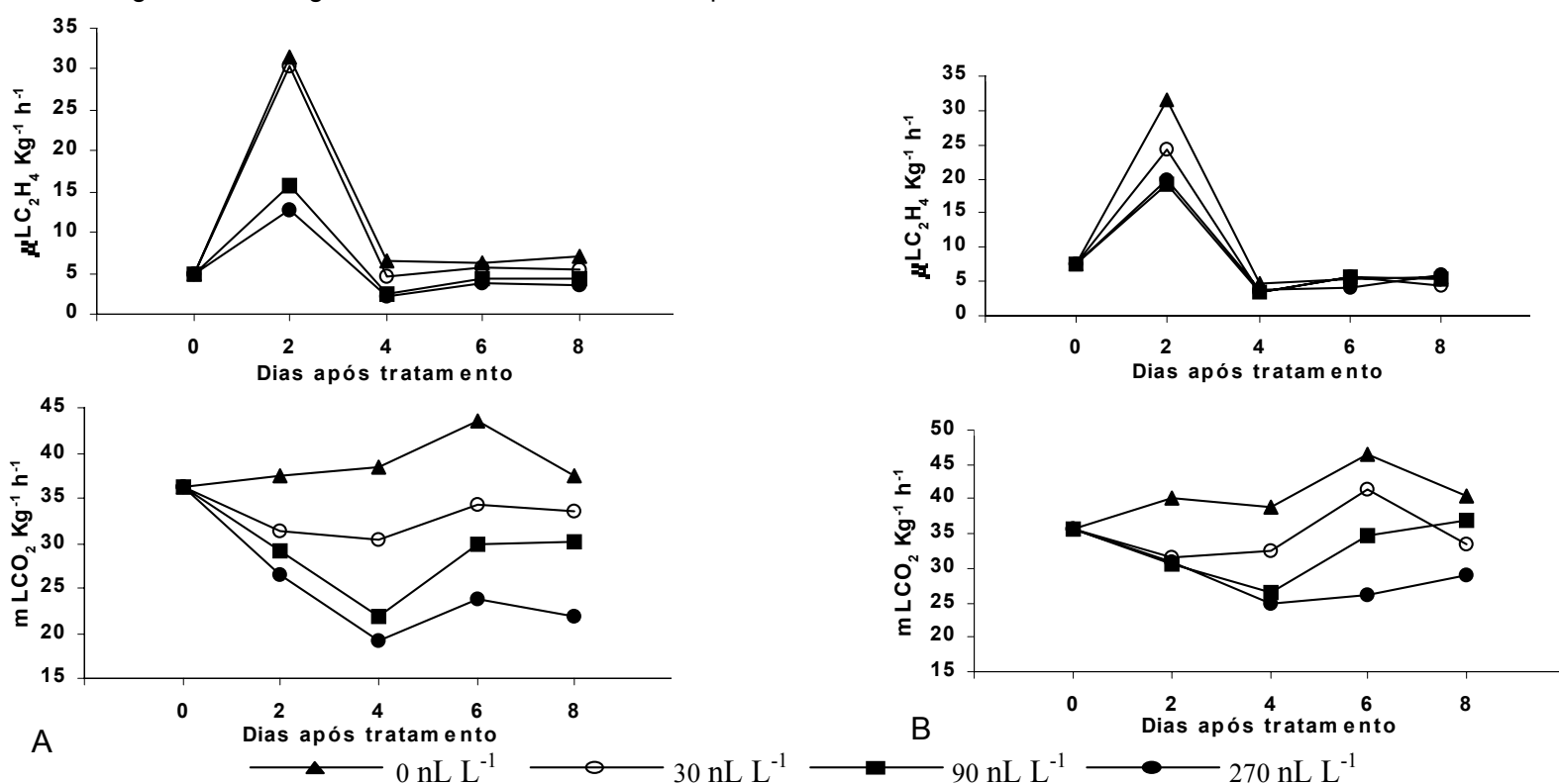

Figura 1 - Efeito do 1-MCP sobre a taxa respiratória e produção de etileno de mamões 'Sunrise Solo' colhidos em dois estádios de maturação. $\mathrm{A}=$ verde $; \mathrm{B}=$ maduro. 

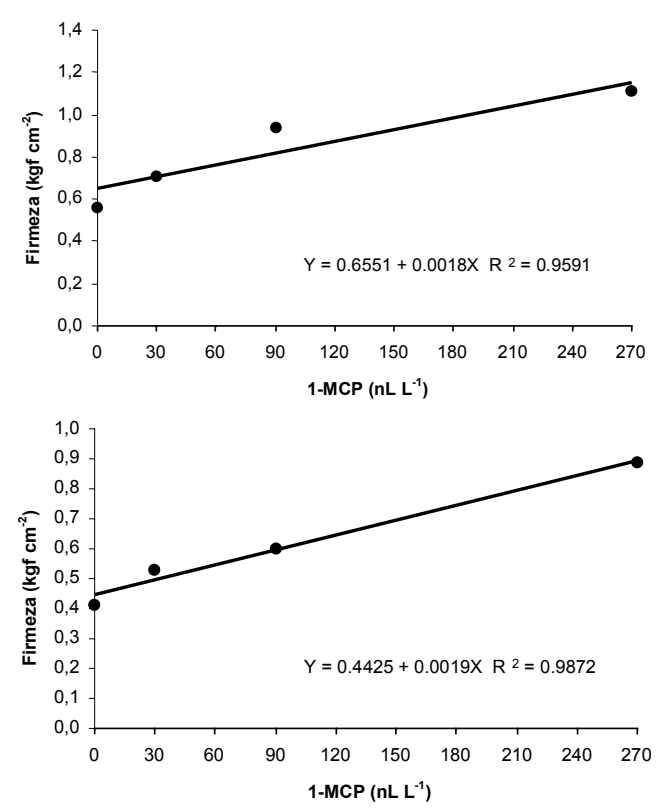

Figura 2 - Efeito da concentração de 1-MCP sobre a firmeza de mamões 'Sunrise Solo' colhidos no estádio verde $(A)$ e maduro (B) e armazenados a $20^{\circ} \mathrm{C}$ durante 6 e 4 dias, respectivamente.

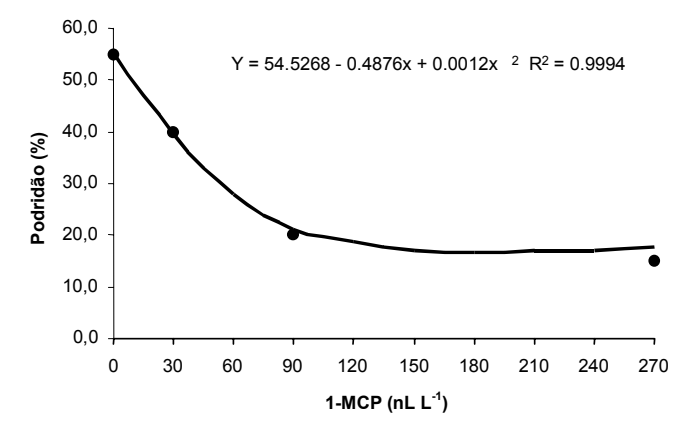

Figura 3 - Efeito da concentração de 1-MCP porcentagem de podridão de mamões 'Sunrise Solo' colhidos no estádio verde e armazenados a $20^{\circ} \mathrm{C}$ durante 6 dias.

A aplicação do 1-MCP aumenta a vida de prateleira de mamões, como consequência da capacidade do 1-MCP de inibir a ação do etileno nos tecidos e retardar o amadurecimento. $O$ aumento no período de conservação sob condições ambientais é importante, considerando a alta perecibilidade do mamão após a colheita. O ganho de dois a três dias de vida de prateleira pode proporcionar transporte dos frutos a maiores distâncias e ampliação do período de comercialização dos mesmos.

\section{REFERÊNCIAS BIBLIOGRÁFICAS}

ABDI, N.; McGLASSON, W.B.; HOLFORD, P.; WILLIAMS, M; MIZRAHI, Y. Responses of climateric and suppressed-climacteric plums to treatment with propylene and 1-methylcyclopropene. Postharvest Biology and Technology, v.14, p.29-39, 1998.
BLANKENSHIP, S.M.; SISLER, E.C. 2,5-norbornadiene retards apple softening. HortScience, v.24, p.313-314, 1989.

BLANKENSHIP, S.M.; SISLER, E.C. Response of apples to diazocyclopentadiene inhibition of ethylene binding. Postharvest Biology and Technology, v.3, p.95-101, 1993.

BURG, S.P.; BURG, E.A. Molecular requirements for the biological activity of ethylene. Plant Physiology, v.42, p.144-152, 1967.

CALBO, A.G.; NERY, A.A. Medida de firmeza em hortaliças pela técnica de aplanação. Horticultura Brasileira, v.13, p.14-18, 1995.

DUPILLE, E.; SISLER, E.C. Effects of ethylene receptor antagonist on plant material. In: AIT-OUBAHOU, A.; EL-OTMANI, M. (Ed.) Postharvest, pathology and technologies for horticultural commodities: recents advances. Agadir: Institute Agronomique et Veterinaire Hassan II., 1995. p.294-301.

FAN, X.; ARGENTA, L.; MATTHEIS, J.P. Inhibition of ethylene action by 1methylcyclopropene prolongs storage life of apricots. Portharvest Biology and Technology, v.20, p.135-142, 2000.

FAN, X.; BLANKENSHIP, S.M.; MATTHEIS, J.P. 1-methylcyclopropene inhibits apple ripening. Journal of the American Society for Horticultural Science, v.124, p.690-695, 1999.

FENG, X.; APELBAUM, A.; SISLER, E.C.; GOREN, R. Control of ethylene responses in avocado fruit with 1-methylcyclopropene. Portharvest Biology and Technology, v.20, p.143-150, 2000.

GOLDING, J.B.; SHEARER, D.; WYLLIE, S.G.; McGLASSON, W.B. Application of 1-MCP and propylene to identify ethylene-dependent ripening processes in mature banana fruit. Portharvest Biology and Technology, v.14, p.87-98, 1998.

GONG, Y.; TIAN, M.S. Inhibitory effect of diazocyclopentadiene on the development of superficial scald in 'Granny Smith' apples. Plant Growth Regulation, v.26, p.117-121, 1998.

JIANG, Y.; JOYCE, D.C.; MACNISH, A.J. Extension of the shelf life of banana fruit by 1-methylcyclopropene in combination with polyethylene bags. Postharvest Biology and Technology, v.16, p.187-193, 1999.

KADER, A.A. Postharvest technology of horticultural crops. Oakland: University of California, 1994.296p.

LELIĖVRE, J.M.; TICHIT, L.; DAO, P.; FILLION, L.; NAM, Y.W.; PECH, J.C.; LATCHÉ, A. Effects of chilling on the expression of ethylene biosynthetic genes in Passe-Crassane pear (Pyrus communis L.) fruits. Plant Molecular Biology, v.33, p.847-855, 1997b.

LELIËVRE, J.M.; LATCHÉ, A.; JONES, B.; BOUZAYEN, M.; PECH, J.C. Ethylene and fruit ripening. Physiologia Plantarum, v.101, p.727-739, 1997a.

McGUIRE, R.G. Reporting of objective color measurements. HortScience, v.27, p.1254-1255, 1992.

NAKATSUKA, A.; SHIOMI, S.; KUBO, Y.; INABA, A. Expression and internal feedback regulation of $A C C$ synthase and $A C C$ oxidase genes in repening tomato fruit. Plant and Cell Physiology, v.38, p.1130-1110, 1997.

PAULL, R.E. Pineapple and papaya. In: SEYMOUR, G.B.; TAYLOR, J.E.; TUCKER, G.A. (Ed.) Biochemistry of fruit ripening. London: Chapman \& Hall, 1993. p.291-323.

PORAT, R.; HALEVY, A.H.; SEREK, M.; BOROCHOV, A. An increase in ethylene sensitivity following pollination is the initial event triggering an increase in ethylene production and enhanced senescence of Phalaenopsis orchid flowers. Physiologia Plantarum, v.88, p.243-250, 1995.

SEREK, M.; SISLER, E.C.; REID, M.S. 1-methylcyclopropene, a novel gaseus inhibitor of ethylene action, improves the life of fruit, cut flowers and potted plants. Acta Horticulturae, v.394, p.337-345, 1995.

SEREK, M.; SISLER, E.C.; REID, M.S. A volatile ethylene inhibitor improves the postharvest life of potted roses. Journal of the American Society for Horticultural Science, v.119, p.572-577, 1994.

SIMÃO, S. Tratado de fruticultura. Piracicaba: FEALQ, 1998. 760p.

SISLER, E.C.; SEREK, M. Inhibitors of ethylene responses in plants at the receptors level: recent developments. Physiologia Plantarum, v.100, p.577-582, 1997.

SISLER, E.C.; SEREK, M.; DUPILLE, E. Comparison of cyclopropene, 1methylcyclopropene, and 3,3-dimethylcyclopropene as ethylene antagonists in plants. Plant Growth Regulation, v.18, p.169-174, 1996.

TUCKER, G.A. Introduction. In: SEYMOUR, G.B.; TAYLOR, J.E.; TUCKER, G.A. (Ed.) Biochemistry of fruit ripening. London: Chapman \& Hall, 1993. p.1-51.

Recebido em 13.12 .00 